\title{
Collective Editorial: Ten Guidelines for Strategic Social Action
}

\author{
José G. Ardila Sánchez ${ }^{1}$ - Traci M. Cihon ${ }^{2}$ (D) Maria E. Malott ${ }^{3}$. \\ Mark A. Mattaini ${ }^{4}$ (D) Richard F. Rakos ${ }^{5} \cdot$ Ruth Anne Rehfeldt $^{6}$ (D) \\ Sarah M. Richling ${ }^{7}$ (D) Kathryn M. Roose ${ }^{1} \cdot$ Holly A. Seniuk $^{8}$. \\ Jomella Watson-Thompson ${ }^{9}$
}

Accepted: 12 October 2020 / Published online: 23 November 2020

(C) Association for Behavior Analysis International 2020

This collective editorial was developed by the Behavior and Social Issues senior editorial staff, the Board of Planners for Behaviorists for Social Responsibility, and several other leaders in behavior science due to our deep concern that the need for strategic activism over the next months and possibly years, in the United States and beyond, may be extensive. In particular, issues like Black Lives Matter; responses to the COVID-19 pandemic; acknowledgment of, much less the response to, climate change; election controversies, and fears of "civil unrest" are only some of the social and environmental issues that many divided societies are currently struggling to address. The challenges being faced often include profound differences in relational responding among groups, often integrated with obvious differences in socioeconomic resources and levels of privilege. Unfortunately, extensive, potentially helpful empirical and historical data regarding strategic options for addressing these issues and sustaining activist patterns are not widely known, even within behavior science. Given the lack of

Mark A. Mattaini

mattaini@uic.edu

1 Department of Psychology, University of Nevada, Reno, Reno, NV, USA

2 College of Health and Public Service, University of North Texas, Denton, TX, USA

3 Association for Behavior Analysis International, Portage, MI, USA

4 Jane Addams College of Social Work, University of Illinois at Chicago, PO Box 1045, Paguate, NM 87040, USA

5 College of Sciences and Health Professions, Cleveland State University, Cleveland, OH, USA

6 Department of Applied Behavior Analysis, Chicago School of Professional Psychology, Chicago, IL, USA

7 Department of Psychological Sciences, Auburn University, Auburn, AL, USA

8 Behavior Analyst Certification Board, Reno, NV, USA

9 Department of Applied Behavioral Sciences, University of Kansas, Lawrence, KS, USA 
access to those resources, a great deal of activist energy is wasted; in fact, some actions meant to resist injustice can be damaging.

Even though much more research is needed (and behavior scientists, largely absent from that research, could make substantial contributions if they engage in it), a great deal is already known about what must be, for scientific reasons, the overall strategic goal: nonviolently constructing and sustaining ecologies of social and environmental justice (Roose \& Mattaini, in press). Gandhi noted that shifting the practices of unjust rulers could only occur "by a change of environment; but the environment are we-the people who make the rulers who they are" (Dear, 2002 , p. 48). As will not be surprising to most behavior scientists, research on nonviolent change indicates that the keys to shifting social and environmental ecologies are accelerating positive interlocking cultural practices and prosocial relational responding. Some forms of decelerative contingencies are required in some cases, but history resoundingly demonstrates that their long-term outcomes are typically limited, particularly when functioning as the primary strategy, and carry grave risks, whether at the local or international level. (The American Revolution is often quoted as an exception, but in fact, a new, independent country had already largely formed and taken control before the fighting began; see Schell, 2003.) However, there are literally thousands of cases of effective nonviolent activism for change (McCarthy \& Sharp, 1997) on every continent except Antarctica, and on average, the results are much better (Chenoweth \& Stephan, 2011; Mattaini \& Roose, in press). As Gandhi (1945) clarified, what is needed to build a healthy and just society is a "constructive programme"- even when that requires constructive noncooperation, as discussed later.

In this collective editorial, we draw from a broad literature to identify and briefly explore 10 culturo-behavioral guidelines for strategic activism. Our hope is that readers will examine this material and the resources that accompany this editorial, and then identify and commit to ways that each of us, or groups of us, can contribute to this overall strategic goal. Many of the authors expect to prepare more comprehensive materials related to these guidelines for later issues of this journal, and are willing to discuss such work in more depth with those interested. The journal also continuously solicits submissions grounded in our science, both as regular articles, and for the Activism and Advocacy Notes section. In collaboration with many others, our science can help. ${ }^{1}$

\section{Guideline 1. Be an Ethical Activist: an Active and Ongoing Process}

A foundational guideline of many established professional codes is to "first, do no harm." Although this may seem straightforward, without a thorough consideration of potential negative externalities (Biglan, 2009b), harm may be an unfortunate byproduct of well-intended actions. Individuals who act from an outside position (i.e.,

\footnotetext{
${ }^{1}$ Included with this article is a Supplement provided by the Community Tool Box, a free online resource that provides tools for social action and change sponsored by the Center for Community Health and Development at the University of Kansas. (To optimize the use of the tools in the Community Tool Box, review Community Tool Box Chapter 1, Section 1: A Community Tool Box Overview and Gateway to the Tools.)
} 
are not a member of the oppressed group) are particularly susceptible to engaging in behaviors that may actually cause serious harm to activist efforts. If one fails to consider the cultural context of the situation or acts without intimate knowledge of the particular conflict, one may provide problematic advice that could have detrimental effects (Sharp \& Raqib, 2010). In some cases, doing no harm may mean not acting at all as an outsider.

When action is warranted, ensuring nonviolence not only aligns with the concept of doing no harm, but has also been demonstrated as more effective than violent approaches (Chenoweth \& Stephan, 2011). As ethical activists, it is our obligation to ensure no harm through our actions, to choose strategies that are the most effective, and to minimize aversive or coercive strategic choices. With respect to actions that may result in physical harm to persons or property, Sharp (1973) argued that such actions can have negative consequences, including injury to innocent people. There are times when damage to symbolic artifacts communicates effectively; one may justify this by creating a relational frame between these actions and the injustices and oppression that are experienced by particular groups. Damage to people or other forms of property, however, is likely for many to be related relationally to criminal or dangerous radical behavior. As ethical activists, we must understand how such verbal constructions may unduly influence our own behavior, as well as that of all others on all sides in campaigns for change.

Actions framed as violent can be conceptualized as retaliatory in nature, and therefore generally ineffective. Mattaini (2013) identified three points drawn from behavior science literature that suggest retaliation is a weak intervention: (a) punishment is difficult and costly, (b) it results in an escalating cycle of retaliation on all sides, and (c) it is associated with various negative side effects including anger, countercoercion, suppression, rigidity, and immobilization. As behavior scientists, we have a responsibility to act as ethical activists who apply our science to improve the world. The remaining guidelines suggest behaviors that we can engage in as we work toward strategic activism. Moreover, we emphasize the importance of continually, actively, and intentionally reflecting on the ethical considerations that are inherent in this work.

\section{Guideline 2. Actively Observe, Learn, and Engage with Local Values, Communities, and Environments}

Given recent shifts in accessibility and safety related to travel, opportunities to engage in strategic action to strengthen one's local community may feel more accessible to many behavior scientists. Strategic action at the local, community level, however, is no less nuanced or challenging than efforts focused at the state, national, and even international levels. Even in those cases, however, it is important to recognize the potential for differences in values, experiences, and dimensions of diversity, and therefore to engage in intentional efforts to minimize colonial or exploitative relationships (e.g., Cihon, Walker, Kazaoka, \& Pritchett, in press; Fawcett, Bernstein, et al., 1988; see also Pritchet, Ala'i, Re Cruz, \& Cihon, in press). The focus of this guideline is working collaboratively with community members and local leadership, as well as being committed and present: 
- Identify and respect local leadership: Communities are systems that consist of multiple interlocking elements that create networks of contingencies that guide community members. These networks, however, are established by the behaviors of the community members, and those who serve in local leadership. Local leaders hold positions of power that provide the opportunity to affect large-scale behavior change. Fawcett, Bernstein, et al. (1988) noted that community leaders are "often very effective behavior change agents, because they understand social support systems and know how to mobilize constituencies" (p. 19). A critical step for behavior scientists engaging in strategic action at the community level is to actively seek out and develop relationships with local leaders. Community leaders are often members of the community affected by both the problems and the potential solutions, and have important firsthand knowledge of the practices and values of the community. The "combination of behavior analysis and community sensitivity could produce culturally-relevant policies that have a greater likelihood of being effectively implemented" (Fawcett, Bernstein, et al., 1988, p. 19).

- Get involved: Behavior scientists frequently serve in the role of consultant, assisting others with incorporating concepts and principles of behavior science into their daily lives. Consulting with community and advocacy groups is certainly one avenue by which behavior scientists can make contributions to nonviolent strategic action campaigns. Another, often more sustainable option would be to become a member of community and advocacy groups, particularly those with similar or shared values, remembering that one can lead from any position within an organization. Joining community or advocacy groups, as a member (and not as a scientistconsultant), provides opportunities to learn from other group members, establish long-lasting relationships, offer support and suggestions regarding initiatives, and volunteer to take the lead on specific action items.

- Increase access to decision makers: Similarly, behavior scientists might consider cultivating relationships with political groups, supporting and coming to know council members and state and federal representatives, and even making campaign contributions. Sustained engagement with those in distinct decision-making positions is advantageous and can provide a different level of access when specific, critical advocacy is needed.

- Commit to participation as one of many repertoires required to achieve change, and be present: The behavior scientist who seeks to support and affect change at the community level is making a commitment to that community; it involves both advocacy and accompaniment (cf. Ardila Sánchez, Richling, Benson, \& Rakos, in press). Such work comes with an obligation to commit, be present, and participate in "a recursive practice in which one observes, reflects, acts based on what is learned, and reflects further on what is observed in action" (Mattaini, 2013, p. 131).

\section{Guideline 3. Explore Individual and Cultural/Collective Relational Responding Relevant to the Current Situation}

Relational framing processes are at the heart of political beliefs and opinions. Political party affiliation involves interactions with a myriad of verbal stimuli. A person's upbringing may teach him or her that the Democratic Party is related by coordination 
with sustainability and gun control, whereas the Republican Party is related by coordination with fossil fuels and gun rights. For individuals with such a learning history, deriving that Republicans and Democrats are opposite is likely; for example, because Democrats often support social welfare, a person may derive that Republicans do not care about the well-being of a society's members (see Dymond \& Rehfeldt, 2000). With White supremacist groups typically identifying as Republican, class merger (Sidman, 1997) may yield an overgeneralized network of linkages between Republican ideology and White supremacy. This process has been shown to apply to racism, religious stereotypes, ageism, and other forms of social categorization (Barnes-Holmes, Murphy, Barnes-Holmes, \& Stewart, 2010; Cullen, Barnes-Holmes, Barnes-Holmes, \& Stewart, 2009; Mattaini \& Rehfeldt, 2020; Weinstein, Wilson, Drake, \& Kellum, 2008). Relational networks can "run wild" outside of the laboratory (see Sidman, 1997) and result in extreme views and misunderstandings.

Media messages and political rhetoric often foster relational framing of this sort. Rakos (1993) identified the deliberate manipulation of stimulus relations in a speech by President George H. W. Bush garnering support for the war in Iraq. President Bush's speech established verbal relations between such stimuli as "helpless, impoverished, downtrodden Kuwait" and "aggressive, weapon-building, murderous Iraq," for the purposes of engineering public support for the war. The same process is very much at play in relation to recent events with the linkages between "protest, civil unrest, Portland, and Black Lives Matter," which are presented frequently in political propaganda. At a time of immense division, it is important for people to be wary of such overgeneralized frames.

Relational framing processes can aid those fighting for social justice by ensuring the dissemination of accurate frames and challenging community behavior that promotes potentially deleterious relational networks. Widespread sit-ins may be more impactful than violent looting for this reason. Changing the functions of verbal stimuli may also be a useful tactic; "humor as resistance" (Mattaini, 2013) was a widespread strategy to oust Yugoslavia's dictator Slobodan Milošević. Humorous messages about the feared leader were presented in theatrical and musical performances and disseminated on badges, T-shirts, and other paraphernalia. Social media campaigns utilizing memes, cartoons, and caricatures may help dismantle faulty frames and establish new ones. Relational framing repertoires allow listeners to follow rules such as augmentals that indirectly increase or decrease behavior because they increase the value of some specified consequence. The circulation of augmentals such as "Don't you want your descendants' rights to be protected?" may set the occasion for letter and phone campaigns to support progressive goals. Gloster, Meyer, and Lieb (2017) found in their data that psychological flexibility can be a malleable public health target.

Engaging in behavior that is consistent with one's values requires a sophisticated repertoire of relational framing. Clarifying one's values, or that which gives one's life meaning, and engaging in committed actions that are consistent with those values may be necessary for individuals who find themselves on all sides of a conflict at this time. Biglan (2009a) suggested that widespread values clarification (e.g., acceptance and commitment training; Biglan, Johansson, Van Ryzin, \& Embry, 2019) may be one step toward promoting a compassionate society that celebrates the uniqueness and diversity of all of its members. 


\section{Guideline 4. Complete Situation-Specific Cultural Systems Analysis}

Culturo-behavior science offers tools to identify interlocking variables and systemic practices within the behavioral, cultural, and ecological milieu that maintain the status quo, and from there, to navigate complex interactions and identify strategic directions for change (Malott, 2016, 2019). In a social movement, whether we attempt to defend human rights, protect the environment, gain freedom from a dictatorship, or pursue any other social cause, it is essential to clarify critical, interlocking systems that play a role in supporting oppression and structural violence. Cultural systems analysis, particularly when integrated into community and transdisciplinary efforts, provides tools for operationalizing social and environmental justice. The process generally begins with gathering contextual information about communities and interdependent systems (Guideline 2) and identifying relevant individual and collective patterns of relational responding (Guideline 3 ) that provide essential data for systemic analysis. That analysis offers guidance for determining "grand" (overall) strategic goals for a movement overall, campaign strategies for achieving meaningful portions of the grand strategy, and flexible short-term tactics supporting the campaigns (Guideline 5).

Robert Helvey (2007), an associate of both the Albert Einstein Institution and the International Center on Nonviolent Conflict, and recipient of the Distinguished Service Cross for his 30 years of service in the military, described the process of preparing a "strategic estimate" for nonviolent struggles. In his words, a strategic estimate

provides a systematic approach to developing the best course of action to complete a mission. It does this by identifying and analyzing important factors such as the environment (physical, military, political) and the capabilities of those expected to be participants (both friendly forces and the opponent), and then compares strengths and vulnerabilities to develop courses of action. (p. 47)

The environment is not seen as a single-layered surface selecting behavior, but rather it is a matrix or milieu wherein multiple historical, sociological, ecological, and psychological factors - what Gene Sharp called "pillars of support" - can shift or maintain the balance of interlocking practices and, in doing so, alter the status quo. An analytic process like this organizes the data obtained by contact with the relevant communities and patterns of identification of related relational responding to guide strategic and tactical decisions (Sharp \& Raqib, 2010).

Behavioral and cultural systems analysis offers several tools that can be useful in operationalizing the relevant dynamics (and all systems analyses are dynamic; it is the interactions among elements that constitute a "system"). The following are three such tools (samples of each are found in Mattaini, 2013, Chapter 4):

- Force field analysis (Lewin, 1943; Mattaini, 2013) produces a graphic depiction of contextual variables supporting (driving forces) and opposing (restraining forces) a desired policy change; if the analysis is accurate, movement toward change can be achieved by increasing driving forces, decreasing restraining forces, or both.

- Community/cultural matrices (Biglan, 1995; Mattaini, 2013) can be used to identify multiple community or cultural systems that could be helpful in reaching a campaign goal (e.g., increases in youth advocacy as an alternative to violence; Aspholm 
\& Mattaini, 2017). For each system, practices that could support targeted activism, practices that could oppose such activism, and relevant incentives, disincentives, and facilitating conditions that might be used to shift those practices are charted, and interactions among those systems identified (e.g., specific targeted practices within one system might increase available reinforcers for another system).

- Diagramming interdependencies of contingencies and related behavioral dynamics within and among multiple systems, by expanding on the contingency diagrams that are widely used in behavior analysis (Mattaini, 2013), also provides an important understanding of the relations among Sharp's "pillars of support."

Such analyses provide the information needed to establish specific strategic and tactical goals (see Guideline 5)

\section{Guideline 5. Clarify and Refine Overall Strategic Goals for the Current Situation}

Gandhi (1927/1983), who explicitly defined his life's work as a series of scientific experiments, indicated,

Civil Disobedience can never be directed for a general cause such as for Independence. The issue must be definite and capable of being clearly understood and within the power of the opponent to yield. This method properly applied must lead to the final goal. (p. 28)

Gene Sharp (2005; Sharp \& Raqib, 2010), a political scientist and perhaps one of the most important nonviolence researchers and activists in the past 100 years, placed heavy emphasis on the need for carefully crafted and continuously updated strategic decisions to guide any campaign for social change. As Sharp (2005) noted, "strategic planning ... enables the nonviolent struggle group to become stronger because it knows where it intends to go and because it is aware of possible problems, events, and reactions that the resisters will likely encounter" (p. 443). Sharp further clarified four possible outcomes: conversion (the opponent embraces the ends of the activist group), accommodation (the opponent agrees to grant some demands), nonviolent coercion (changes in conditions require the opponent to concede), and disintegration (the regime falls). In nonviolent social action, strategic choices typically depend on which of these options appears both possible and most consistent with the values of the resistance group.

Behavior science offers some unique help for strategic planning. Israel Goldiamond (1974/2002; Layng, 2009), in his nonlinear constructional model, strongly recommended that efforts to address social problems should, to the extent possible, emphasize constructing new patterns of behavior to replace problem patterns, rather than emphasizing suppression of undesirable behavior, which could risk violation of human rights and the undesirable effects of coercion. Mattaini (2013) noted that "a first strategic goal of many resistance movements is most often to stop or reduce exposure of the population to pain, suffering, torture, or other aversive events" (p. 61). Strategic options like persuasion and protest as discussed in Guideline 6 are often important for 
achieving such goals. Ultimately, however, strategic goals in most cases should focus on constructing interdependent patterns of cultural processes that shape and sustain cultural ecologies of justice. Constructive noncooperation (see Guideline 6) is often the optimal choice for achieving that goal. Two additional resources - analyses of current relevant individual and collective relational responding (Guideline 3) and cultural systems analytic skills (Guideline 4) — can be particularly helpful in selecting strategic options for a specific campaign.

\section{Guideline 6. Consider and Collectively Select Strategic and Tactical Options}

Many strategic and tactical options have been implemented worldwide to facilitate social change (see, e.g., McCarthy \& Sharp, 1997; Schell, 2003). Sharp (1973, 2013), for example, identified 198 methods from the history of nonviolent struggle, each with actual cases, that could be woven into strategic planning. Recognizing Sharp's enormous contributions, Mattaini (2013) developed a behavioral systems classification of those 198 methods. From those data, he identified six classes of strategic options. One option - retaliation - is generally a poor choice (see Guideline 1). Each of the other five, however, has a valuable place in nonviolent activism; strategically mixing and phasing them can escalate their impact. Detailed descriptions of each, and combinations among them, are found in Mattaini (2013).

- Persuasion generally results from one of three processes: (a) the provision of additional reinforcement contingent on the performance of desired actions by target systems or persons, (b) the provision of additional information indicating that the performance will provide such reinforcement, or (c) shifts in relational responding that change the value of taking the desired action (see Guideline 3).

- Protest, often integrated with efforts to persuade, is based on negative reinforcement - undesirable conditions are threatened or established that the target systems or persons can avoid or escape through compliance with the goals of the activists. In the cases of both persuasion and protest, the contingencies driving change may come primarily from others (e.g., allies of the decision maker or committed citizen's groups), with activists focusing on contingencies directed toward members of those groups - interventions that can be designed based on analysis of relevant behavioral systems dynamics (see Guideline 4).

- Disruptive noncooperation methods rely on making it difficult or impossible for the target person or system to continue to function in ways that damage oppressed groups. The primary behavioral dynamic here is extinction - essentially, activists and communities refuse to comply regardless of the actions taken by the opponent. As is typical of extinction, the opponent is likely, initially, to escalate coercive responses; activists must therefore be prepared to persist through that escalation. If they yield in response, activists will have reinforced the use of more aversive actions by opponents. Extinction can be powerful but often challenging to maintain; considerable commitment is therefore required.

- Resource disruption involves eliminating or reducing the opponent's ability to continue coercive or oppressive practices by interfering with the availability of 
the resources required to continue those practices. Examples include actions like shutting down the electricity in a community or blocking access to food for invading troops. In some cases, the line between disruptive noncooperation and resource disruption is somewhat permeable, but the behavioral dynamics are different.

- Constructive noncooperation is in many cases the most powerful but most difficult option. In this case, the activist group not only limits cooperation in the coercive practices of opponents, disrupting those systems, but also establishes alternative systems to meet the needs of the struggling population. Examples include setting up support communities that provide respectful service and active voice to homeless populations as an alternative to inadequate and unsafe government facilities, or neighborhood organizations establishing restorative justice systems while refusing to call on the police (and potentially reducing resources directed to them) for many kinds of cases.

\section{Guideline 7. Mobilize—or Organize?}

Successful movements must (a) attract large numbers (i.e., mobilize) and (b) effectively coordinate and sustain the actions of participants toward common goals (i.e., organize). "Mass participation" is a critical component of successful resistance movements (Chenoweth \& Stephan, 2011, p. 30). In their review of decades of violent and nonviolent movements, Chenoweth and Stephan (2011) found evidence that nonviolent campaigns are typically more effective in recruiting participants than violent campaigns, even when controlling for the size of the population of the country in which they occur. Thus, in addition to the previously mentioned benefits of nonviolent movements when compared to violent movements, another benefit is that recruitment into nonviolent movements is much easier.

Mobilization is important; however, "organization is the pathway to power" (Stephan \& Thompson, 2018, para. 7). Much energy in resistance campaigns is wasted through lack of coordination. The shift from organization to mobilization is crucial for achieving the outcomes valued by the movement. It has been noted that "youth movements fizzle when they fail to forge broad-based alliances, sustain pressure on power holders or organize around a compelling alternative vision" (Stephan \& Thompson, 2018, para. 7). Movements that mobilize but fail to organize have been criticized for failing to develop strategies to turn their energy and efforts into legislative or electoral change. For example, the Occupy Wall Street movement was considered unsuccessful due to a lack of strong goals and efforts to make lasting changes, and the movement that forced the resignation of Hosni Mubarak in Egypt did not organize around an acceptable replacement, which resulted in new leadership that was similarly oppressive (Stephan \& Thompson, 2018). As one historian summarized, "Occupy Wall Street, like many radical movements, was much better in critique than in political agenda" (Stewart, 2019 para. 25) Replace "Occupy Wall Street" in the quote with the name of almost any failed resistance movement, and the problem becomes clear.

Notably, movements may fade away in apparent failure but reappear in a similar or new format. For example, although the Occupy movement was deemed unsuccessful, new analyses indicate that ideas and slogans from the movement persist to this day, 
almost 10 years later. For example, Occupy Wall Street brought the phrase " 99 percent" into the public space, referring to the disproportionate wealth of a very small portion of the world population, and splinter groups distantly related to the original movement have sprung up and impacted legislation (e.g., Occupy the SEC, Occupy Homes, Occupy Sandy; Stewart, 2019). Similarly, although the Black Lives Matter movement has been criticized in the past for a lack of meaningful outcomes, the resurgence of the movement in 2020 has been connected to 368 bills regulating police practices in 29 states (CSG Justice Center Staff, 2020).

One way to support continued mobilization and organization is through the use of social media. There is no denying that social media provide support for recruitment, fundraising, communication within groups, and dissemination of information; however, the importance of physical presence and participation is typically indispensable for resistance movements with challenging goals (e.g., Gladwell, 2010; Mattaini \& Roose, in press).

\section{Guideline 8. Support the Development of Effective and Sustainable Collective Leadership}

Certain resistance movements are synonymous with their charismatic leaders; Martin Luther King, Jr., and Gandhi, for example, are icons of nonviolent resistance. However, recent evidence supports a relatively universal need for a network of many leaders organizing pockets of coordinated movements in alignment with an overall strategyno movements succeed with only a single leader (Stephan \& Gallagher, 2019). This type of shared leadership has been called "leader-full" by some, including human rights activist Johnson Yeung, who stated,

A decentralized, leader-full movement is resilient against an authoritarian regime.... When you have a leader-full movement it's very hard to pick a target ... the movement will survive because everyone will take ownership of the movement. (Hui, 2019, para. 12)

Rather than the actual leadership structure, the practices of the leader(s) will have a significant impact on the success and sustainability of the movement. Behavioral systems analysis provides some insight into several leadership practices that are particularly relevant for community-based strategic action (see Houmanfar \& Mattaini, 2016; Mattaini, 2013):

- Clarity and communication: Effective leaders communicate clear goals along with the behaviors needed to accomplish the goals, stating both the behaviors and the probable, corresponding contingencies (cf. Houmanfar, Rodrigues, \& Smith, 2009). This differs, however, from telling people what to do; instead, it is creating the conditions such that all those involved know both the strategy and the goal, such that members can behave and/or coordinate responding in ways that facilitate the interlocking practices among the various subsystems, maximizing progress toward shared outcomes (Mattaini, 2013). 
- Structuring recognition and reinforcement: Behavior scientists engaged in strategic action at the community level can support local leadership in appreciating the importance of recognition and the role of reinforcement across various stages of strategic action. Contributions from behavior science suggest the skillful use of recognition and reinforcement to strengthen specific behaviors and practices, such as exemplary performance, the use of participatory approaches (Cihon et al., in press; Fawcett, 1991; Fawcett, Seekins, \& Silber, 1988; Fawcett, Seekins, Whang, Muiu, \& Suarez de Balcazar, 1982), and actions that foster developing cultures of support and communities of practice (Wenger, 2000), such that members also incorporate recognition into reinforcement in their own practices.

- Sources of strategic capacity: The sustainability of a movement depends on constantly recruiting new leadership, sharing power, incorporating a diversity of thought, spending time developing a unity of thought through strategies like circle processes (cf. Mattaini \& Holtschneider, 2017), and ensuring connections between leadership and the grievance populations. Leadership practices that compete with those contingencies established by those outside of the grievance population and the creation of feedback loops that maintain accountability to the community itself can support the continued alignment with the goals of the local community members.

- Avoiding aversive practices: The use of aversives by leadership can be appealing, particularly when under considerable stressors or time constraints, which can be common in community-based strategic action. Behavior scientists, however, are all too aware of the short- and long-term considerations that come with the use of aversive practices (cf. Sidman, 2000). Therefore, along with supporting community leadership in adopting the desirable practices already mentioned, behavior scientists can support the establishment of performance management contingencies (Malott, 2003) that emphasize conflict resolution and constructional strategies in place of the use of aversives (Mattaini, 2013).

\section{Guideline 9. Encourage and Sustain Solidarity and Discipline}

Martin Luther King, Jr., tells us, "We shall have to have people tied together in a longterm relationship, instead of the evanescent enthusiasts who lose their experience, spirit, and unity because they have no mechanism that directs them to new tasks" (Burns, 2004, p. 110). Nonviolent struggle is a collective exercise. Leadership is important (Guideline 8), but successful nonviolent struggle also demands a collective commitment to common goals, often over an extended period of time. Solidarity and discipline are practices central to maintaining that commitment within an activist culture (Helvey, 2007; Sharp, 2005). Solidarity ("unity" in some of the literature) emerges from a common vision, high levels of mutual support, a clearly stated purpose, and a persuasive strategic vision. A record of success is also important for increasing participation (Chenoweth \& Stephan, 2011). Nonviolent discipline is, however, often the greatest challenge to maintain in "actions," as striking out against aversive treatment is characteristic of living organisms - including people. Historical experience viewed through a behavior science perspective, however, provides significant guidance both for building and maintaining solidarity and discipline. 
Two elements of establishing and sustaining solidarity capture much of what is known: maintaining morale and political education. Behavior science offers a framework for achieving each of these goals, grounded in both individual and interlocking collective contingencies (Mattaini, 2013). Strategies for maintaining morale include maintaining rapport, generating incentives to carry on the struggle, reducing grounds for giving up the struggle, and using restraints or sanctions (only when essential, considering the impact of aversives; Sharp, 2005). Political education, both for activists and the broader population, has proven universally critical for sustained campaigns. Such education is grounded primarily in shifting relational networks that enhance pliance (via socially mediated reinforcement for following rules) and tacting (extracting rules consistent with goals from personal observation; see Guideline 3). Behavior scientists are uniquely qualified to plan and implement such education. But both intensive study of the literature in this area and significant personal experience are required for effective implementation — one must know the territory (see Guideline 3; Mattaini, 2013).

Nonviolent discipline refers to maintaining adherence to a minimum set of standards for behavior as a member of a nonviolent activist group. Sharp (2005) indicated that such discipline includes staying with the action once one has engaged, refusing to submit to fear, committing to nonviolent behavior regardless of provocation, and complying with collectively established plans and instructions. One historically grounded approach has been the development of "codes" that spell out expectations. A valuable example demonstrating the serious nature of nonviolent activism is the "CORE Rules for Action" (Congress for Racial Equality, 1963/1995). This code includes 10 guarantees each participant makes to the group (e.g., "[they] will meet the anger of any individual or group in the spirit of good will and creative reconciliation: [they] will submit to assault and will not retaliate in kind by act or word," p. 221). The group reciprocally makes three guarantees to the individual (e.g., "A CORE member shall receive the uncompromising support of [their] CORE group as they face any difficulties resulting from their authorized activities," p. 222). Such a code makes the seriousness of the endeavor clear to all, strengthens shared values among group members (see Guideline 3), and offers specific guidance regarding the patterns of interlocking contingencies required. Activism supporting justice is demanding - and often requires courage.

\section{Guideline 10. Shaping Courage: "Standing in the Fire"}

Nonviolent resistance is an exercise of power. Struggles for justice are not always safe. Extraordinary courage may be required in cases of severe repression; even relatively modest campaigns may evoke expected or unexpected resistance from opponents or even friends and colleagues with different perceptions (relational responses) regarding the issue. Gandhi spoke of courage in nonviolent struggle in this way: "Let me say in all humility that nonviolence belongs to the brave. ... The virtues of mercy, nonviolence, love and truth in any one can be truly tested only when they are pitted against ruthlessness, violence, hate, and untruth" (Dear, 2002, pp. 125-126). Much of the literature, however, has emphasized managing fear more than evoking courage. Helvey (2007) devoted an entire chapter in his small book to fear, offering guidance from study of the historical record, 
including avoiding putting participants into too many overwhelmingly fearful situations, preparing participants so they know what to expect, supplying "rules for action" (e.g., Congress of Racial Equality, 1963/1995), providing assurance and encouragement from respected leaders, establishing common symbols of solidarity, and giving participants specific tasks on which to focus (all quite behavioral practices).

A primary focus on reducing fear is, however, not adequate and not consistent with what is known about relational responding. Emphasizing building courage even when experiencing powerful fear is empirically the stronger choice, and the choice for which we have more powerful procedures. In terms of encouraging and maintaining courage, the following three principles (Mattaini, 2013) are particularly supported by culturobehavioral systems science:

- Accepting fear facilitates action. Work over the past three decades focused on acceptance and mindfulness is proving extremely robust for understanding the dynamics of behavior change for individuals and communities (see Guideline 3). For example, efforts to directly eliminate fear and anxiety are likely to fail, often eliciting anxiety about anxiety in addition to the original problem. Far more effective are approaches that accept fear as natural given one's situation and life experiences; such acceptance enables the potential activist to shift from "I value justice, and I would like to participate in the resistance movement, but I am too afraid of the danger" to "I value justice, and I am afraid, that is natural; nonetheless, I am committing because I truly care about this issue." One can be mindful of one's fear while defusing ("de-fusing," separating that emotion from an action commitment grounded in one's core values; Hayes, Strosahl, \& Wilson, 2009).

- Participation increases fearlessness. Repeated exposure to a feared stimulus can reduce the level of arousal experienced. Such exposure can be achieved in several ways, but in vivo graduated exposure, in which a person directly experiences increasing intensities of the feared situation, is often the most natural and easy to arrange in activist settings through increasingly challenging field assignments. Exposure can also be simulated to some extent through activism training using behavioral skills training. Immersion in a culture of courage can also progressively strengthen individual participants through modeling, habituation, and mutual reinforcement.

- "One fire kindles another" (Deming, 1971). "Standing in the fire" together can reverberate and propagate through a collective over time. As one brave act is emitted, further variations, some even more courageous, are likely to emerge, strengthening escalating cycles of courageous action.

Supplementary Information The online version contains supplementary material available at https://doi.org/ $10.1007 / \mathrm{s} 42822-020-00038-8$.

Author Note The authors' names are listed in alphabetical order, as all are regarded as having contributed equally to this submission.

\section{Compliance with Ethical Standards}

Conflict of Interest We have no known conflicts of interest to disclose. 


\section{References}

Ardila Sánchez, J. G., Richling, S. M., Benson, M. L., \& Rakos, R. F. (in press). Activism, advocacy, \& accompaniment. In T. M. Cihon \& M. A. Mattaini (Eds.), Behavior science perspectives on culture and community. New York, NY: Springer.

Aspholm, R. R., \& Mattaini, M. A. (2017). Youth activism as violence prevention. In P. Sturmey (Ed.), The Wiley handbook of violence and aggression (pp. 1-12). Hoboken, NJ: Wiley. https://doi.org/10.1002/ 9781119057574.whbva104

Barnes-Holmes, D., Murphy, A., Barnes-Holmes, Y., \& Stewart, I. (2010). The implicit relational assessment procedure: Exploring the impact of private versus public contexts and the response latency criterion on pro-White and anti-Black stereotyping among White Irish individuals. The Psychological Record, 60(1), 57-79. https://doi.org/10.1007/BF03395694

Biglan, A. (1995). Changing cultural practices: A contextualist framework for intervention research. Reno, NV: Context Press.

Biglan, A. (2009a). Increasing psychological flexibility to influence cultural evolution. Behavior and Social Issues, 18(1), 15-24. https://doi.org/10.5210/bsi.v18i1.2280

Biglan, A. (2009b). The role of advocacy organizations in reducing negative externalities. Journal of Organizational Behavior Management, 29(3), 215-230. https://doi.org/10.1080/01608060903092086

Biglan, A., Johansson, M., Van Ryzin, M., \& Embry, D. (2019). Scaling up and scaling out: Consilience and the evolution of more nurturing societies. Clinical Psychology Review, 81, 1-12. https://doi.org/10.1016/j. cpr.2020.101893

Burns, S. (2004). To the mountaintop: Martin Luther King's sacred mission to save America: 1955-1968. New York, NY: Harper San Francisco.

Chenoweth, E., \& Stephan, M. J. (2011). Why civil resistance works: The strategic logic of nonviolent conflict. New York, NY: Columbia University Press.

Cihon, T. M., Walker, D. J., Kazaoka, K., \& Pritchett, M. (in press). Ethics for cultural behavior science and practice. In T. M. Cihon \& M. A. Mattaini (Eds.), Behavior science perspectives on culture and community. New York, NY: Springer.

Congress of Racial Equality. (1995). CORE rules for action. In L. Lynd \& A. Lynd (Eds.), Nonviolence in America (pp. 220-222). Maryknoll, NY: Orbis Original work published 1963.

CSG Justice Center Staff. (2020, July 17). States taking action: Law enforcement. Retrieved November 12, 2020 from https://csgjusticecenter.org/states-taking-action-law-enforcement/.

Cullen, C., Barnes-Holmes, D., Barnes-Holmes, Y., \& Stewart, I. (2009). The implicit relational assessment procedure (IRAP) and the malleability of ageist attitudes. The Psychological Record, 59(4), 591-620. https://doi.org/10.1007/BF03395683

Dear, J. (2002). Mohandas Gandhi essential writings. Maryknoll, NY: Orbis Books.

Deming, B. (1971). Revolution and equilibrium. New York, NY: Grossman.

Dymond, S., \& Rehfeldt, R. A. (2000). Understanding complex behavior: The transformation of stimulus functions. The Behavior Analyst, 23, 239-254. https://doi.org/10.1007/bf03392013

Fawcett, S. B. (1991). Some values guiding community research and action. Journal of Applied Behavior Analysis, 24(4), 621-636.

Fawcett, S. B., Bernstein, G. S., Czyzewski, M. J., Greene, B. F., Hannah, G. T., Iwata, B. A., et al. (1988). Behavior analysis and public policy. The Behavior Analyst, 11(1), 11-25. https://doi.org/10.1007/ BF03392450

Fawcett, S. B., Seekins, T., \& Silber, L. (1988). Low-income voter registration: A small-scale evaluation of an agency-based voter registration strategy. American Journal of Community Psychology, 16, 751-758. https://doi.org/10.1007/bf00930024

Fawcett, S. B., Seekins, T., Whang, P. L., Muiu, C., \& Suarez de Balcazar, Y. (1982). Involving consumers in decision-making. Social Policy, 13, 36-41.

Fawcett, S. B., Suarez de Balcazar, Y., Whang-Ramos, P. L., Seekins, T., Bradford, B., \& Mathews, R. M. (1988). The Concerns Report: Involving consumers in planning for rehabilitation and independent living services. American Rehabilitation, 14(3), 17-19.

Gandhi, M. K. (1945). Constructive programme: Meaning and place. Ahmedabad: The Navajivan Trust.

Gandhi, M. K. (1983). Autobiography: The story of my experiments with truth. New York, NY: Courier Dover Publications (Original work published 1927).

Gladwell, M. (2010, October 4). Small change: Why the revolution will not be tweeted. The New Yorker. Retrieved November 12, 2020 from https:/www.newyorker.com/magazine/2010/10/04/small-changemalcolm-gladwell. 
Gloster, A. T., Meyer, A. H., \& Lieb, R. (2017). Psychological flexibility as a malleable public health target: Evidence from a representative sample. Journal of Contextual Behavioral Science, 6(2), 166-171.

Goldiamond, I. (2002). Toward a constructional approach to social problems: Ethical and constitutional issues raised by applied behavior analysis. Behavior and Social Issues, 11, 108-197. https://doi.org/10.5210/bsi. v11i2.92 (Original work published 1974).

Hayes, S. C., Strosahl, K. D., \& Wilson, K. G. (2009). Acceptance and commitment therapy. Washington, DC: American Psychological Association.

Helvey, R. L. (2007). On strategic nonviolent conflict: Thinking about the fundamentals (2nd ed.). East Boston, MA: Albert Einstein Institution.

Houmanfar, R., Rodrigues, N. J., \& Smith, G. S. (2009). Role of communication networks in behavioral systems analysis. Journal of Organizational Behavior Management, 29(3-4), 257-275. https://doi.org/10. 1080/01608060903092102

Houmanfar, R. A., \& Mattaini, M. A. (2016). Leadership and cultural change: Implications for behavior analysis. The Behavior Analyst, 39, 41-46. https://doi.org/10.1007/s40614-016-0064-7

Hui, M. (2019, November 19). What the Hong Kong protests can teach the world about enduring social movements. Quartz. Retrieved November 12, 2020 from https:/qz.com/1695788/the-hong-kongprotests-epitomize-a-resilient-social-movement/

Layng, T. J. (2009). The search for an effective clinical behavior analysis: The nonlinear thinking of Israel Goldiamond. The Behavior Analyst, 32(1), 163-184. https://doi.org/10.1007/BF03392181

Lewin, K. (1943). Defining the "field at a given time". Psychological Review, 50(3), 292-310. https://doi.org/ $10.1037 / \mathrm{h} 0062738$

Malott, M. E. (2003). Paradox of organizational change: Engineering organizations with behavioral systems analysis. Oakland, CA: Context Press.

Malott, M. E. (2016). Selection of business practices in the midst of evolving complexity. Journal of Organizational Behavior Management, 36(2-3), 103-122. https://doi.org/10.1080/01608061.2016. 1200511

Malott, M. E. (2019). How a Few Individuals Brought about a Cultural Cusp: From a Mexican Mural Program to a Movement. Perspectives on Behavior Science, 42(4), 773-814.

Mattaini, M. A. (2013). Strategic nonviolent power: The science of Satyagraha. Edmonton, AB, Canada: Athabasca University Press.

Mattaini, M. A., \& Holtschneider, C. (2017). Collective leadership and circles: Not invented here. Journal of Organizational Behavior Management, 37(2), 126-141. https://doi.org/10.1080/01608061.2017.1309334

Mattaini, M. A., \& Rehfeldt, R. A. (2020). Rendezvous with truth and discovery. Behavior and Social Issues. Advance online publication. https://doi.org/10.1007/s42822-020-00034-y

Mattaini, M. A., \& Roose, K. M. (in press). Organization and leadership in resistance movements: Constructing justice. In R. A. Houmanfar, M. Fryling, \& M. P. Alavosius (Eds.), Applied behavior science in organizations: Consilience of historical and emerging trends in organizational behavior. New York, NY: Springer.

McCarthy, R. M., \& Sharp, G. (1997). Nonviolent action: A research guide. New York, NY: Garland.

Pritchet, M., Ala'i, S., Re Cruz, A., \& Cihon, T. M. (in press). Social justice is the spirit and aim of an applied science of human behavior: An examination and reflection on the variables related to moving from colonial to participatory research practices [Special section]. Behavior Analysis in Practice. https://doi. org/10.31234/osf.io/t87p4.

Rakos, R. F. (1993). Propaganda as stimulus control: The case of the Iraqi invasion of Kuwait. Behavior and Social Issues, 3, 35-62. https://doi.org/10.5210/bsi.v3i1.198

Roose, K. M., \& Mattaini, M. A. (in press). Challenging violence: Toward a 21 st century, science-based "constructive program". In T. M. Cihon \& M. A. Mattaini (Eds.), Behavior science perspectives on culture and community. New York, NY: Springer.

Schell, J. (2003). The unconquerable world: Power, nonviolence, and the will of the people. London, UK: Macmillan.

Sharp, G. (1973). The dynamics of nonviolent action: Part three of the politics of nonviolent action. Boston, MA: Porter Sargent.

Sharp, G. (2005). Waging nonviolent struggle: 20th century practice and 21st century potential. Manchester, NH: Extending Horizons Books.

Sharp, G. (2013). How nonviolent struggle works. East Boston, MA: Albert Einstein Institution.

Sharp, G., \& Raqib, J. (2010). Self-liberation: A guide to strategic planning for action to end a dictatorship or other oppression. East Boston, MA: Albert Einstein Institution.

Sidman, M. (1997). Equivalence relations. Journal of the Experimental Analysis of Behavior, 68(2), 258-266. https://doi.org/10.1901/jeab.1997.68-258 
Sidman, M. (2000). Coercion and its fallout (Rev. ed.). Boston, MA: Authors Cooperative.

Stephan, M. J., \& Gallagher, A. (2019, December 13). Five myths about protest movements: No, protests don't really require charismatic leaders. The Washington Post. Retrieved November 12, 2020 from https:// www.washingtonpost.com/outlook/five-myths/five-myths-about-protest-movements/2019/12/12/ 700a8afc-1d1d-11ea-87f7-f2e91143c60d_story

Stephan, M. J., \& Thompson, T. P. (2018, April 4). Why you should never underestimate a bunch of wellorganized teenage protesters. The Washington Post. Retrieved November 12, 2020 from https://www. washingtonpost.com/news/democracy-post/wp/2018/04/04/why-you-should-never-underestimate-abunch-of-well-organized-teenage-protesters/

Stewart, E. (2019, April 30). We are (still) the 99 percent. Vox. Retrieved November 12, 2020 from https:// www.vox.com/the-highlight/2019/4/23/18284303/occupy-wall-street-bernie-sanders-dsa-socialism

Weinstein, J. H., Wilson, K. G., Drake, C. E., \& Kellum, K. (2008). A relational frame theory contribution to social categorization. Behavior and Social Issues, 17, 40-65. https://doi.org/10.5210/bsi.v17i1.406

Wenger, E. (2000). Communities of practice and social learning systems. Organization Articles, 7(2), 225246. https://doi.org/10.1177/135050840072002 